Research Article

\title{
Formulation of Insect Chitosan Stabilized Silver Nanoparticles with Propolis Extract as Potent Antimicrobial and Wound Healing Composites
}

\author{
Mohammed S. Al-saggaf $(\mathbb{D}$ \\ College of Science and Humanitarian Studies, Shaqra University, Quwaiiyah 11971, Saudi Arabia \\ Correspondence should be addressed to Mohammed S. Al-saggaf; dr.alsaggaf10@gmail.com
}

Received 27 February 2021; Revised 10 April 2021; Accepted 5 June 2021; Published 16 June 2021

Academic Editor: R. Saravanan

Copyright (c) 2021 Mohammed S. Al-saggaf. This is an open access article distributed under the Creative Commons Attribution License, which permits unrestricted use, distribution, and reproduction in any medium, provided the original work is properly cited.

\begin{abstract}
Skin wounds are frequently influenced with microbial infections and inflammation, which need innovative agents for disputing them. Chitosan (Csn) was extracted from larvae of BSF "black soldier fly, Hermetia illucens" and ethanolic propolis extract (Pro) was employed for synthesizing silver nanoparticles (Ag-NPs), using facile biogenic protocol. The BSF-Csn was acquired with a yield of 1.56\%, 91.3\% deacetylation degree, and 88.600 Dalton molecular weight. The Ag-NPs were effectually biosynthesized using Pro, with a mean diameter of $8.73 \mathrm{~nm}$ and zeta potential of $-21.34 \mathrm{mV}$. The antimicrobial activities assessment of insect Csn, Pro, synthesized Ag-NPs with Pro, and their composite against skin pathogens (Staphylococcus aureus and Candida albicans) revealed the elevated efficiency of the individual agents and the superior action of their composite (Csn/Pro/Ag-NPs), with 26.3 and $23.4 \mathrm{~mm}$ inhibition zones and inhibitory concentrations of 35.0 and $45.0 \mu \mathrm{g} / \mathrm{mL}$ from the composite toward $S$. aureus and C. albicans, respectively, which exceeded the actions of commercial antibiotics. The treatment of rat's wounds with this composite promisingly led to faster healing of wounds and absence of inflammation and infection signs. The powerful actions of Csn/Pro/Ag-NPs as antimicrobial and wound healing composite strongly advocate their applications for skin protection, disinfection, and regeneration.
\end{abstract}

\section{Introduction}

Chitosan (Csn), the derived amino-polysaccharide from chitin deacetylation, is a superior biopolymer that has numerous applications in the biological and medical fields. Accordingly, more Csn extraction processes were greatly required from any potential source, including crustacean wastes, fungi, plants, or insects [1]. Crustacean are the foremost sources for Csn acquiring, but due to their seasonal limited supply, the Csn extractions from fungi and insects were explored as promising alternative sources [2]. The estimation of insect species number is ranging from 6 to 10 million, which exceeds all other animal species together [3]. The BSF could be cultivated for utilization as rich protein sources in animal, poultry, and fish feeding; these insects have also remarkable amounts of chitin in their exoskeleton, which are usable for
Csn extraction $[4,5]$. The Csn extraction was exploited from many insects, including Apis mellifera, Calosoma rugosa, Schistocerca gregaria, and Hermetia illucens "BSF, Black soldier fly" $[2,5-7]$. The Csn bioactivities were recurrently verified as promising antimicrobial, clarifying, biochelating, antioxidant, antifungal, and healing accelerator agent [712]. The conjugating of Csn with other bioactive compounds and nanomaterials was proposed to augment its biological activity, e.g., antifungal and anticancerous activity $[13,14]$.

The nanotechnology and nanomaterials' applications in human daily life became an actuality, including their increasing usage in biomedical and health-related fields [15]. The nanomaterials' wide-ranging applications enforced the investigations for more efficient and ecofriendly methods to synthesized/manipulate these nanoforms [16]. The conventional synthesizing protocols (physical and chemical) have 
several limitations in metal nanoparticles preparation, e.g., toxic chemicals, high-energy requirements, and expensive downstream processes [17].

The "Green synthesis/biosynthesis" strategies involve the employment of environmentally compatible agents/compounds from biological sources (plants, bacteria, biopolymers, fungi, etc.) for nanoparticles' synthesizing [16]; these auspicious strategies have many advantages over conventional methods, i.e., they produce speedy, eco-friendly, costeffective, high yield, and safer nanoparticles [15].

Silver nanoparticles (Ag-NPs) are form the leading studied nanometals that have elevated potentialities for applying as powerful antimicrobial, anticancer, antioxidant, and wound-healing accelerator agents; they could be effectually synthesized via biogenic protocols, which augment their eco-friendly characteristics, biocompatibility, and safety toward human cells [18-24].

Numerous reports employed plant extracts/derivatives for synthesizing and stabilizing Ag-NPs, with elevated microbial-inhibition properties $[17,19,25,26]$; the plants phytocompounds were serving as reducing/capping agents while reacting with $\mathrm{AgNO}_{3}$ (the commonly exercised precursor for Ag-NPs synthesis), which can effectually increase the functionality, bioactivity, and eco-friendly attributes of the protocol.

Propolis (Pro) is the natural beehive resinous composite that is collected from exudates and buds of diverse plants by honeybees, amalgamated with wax, pollen and bees' enzyme. Pro exhibited numerous bioactive compounds and bioactivities and was effectually employed in plentiful pharmacological and biomedical applications [27], including its powerful antimicrobial action, inflammatory, antioxidant, and wound healing potentiality [2830]. The bee Pro could efficiently synthesize metals' NPs (e.g., silver, gold, and selenium), stimulated by Pro content from biomolecules like flavonoids, alkaloids, phenols, terpenoids, and steroids [31-33].

Wound healing comprises complicated multistep processes affected with varied external and internal factors; skin injury is regularly accompanied by microbial infections and apparent inflammation [34]; these added aspects direct to further required therapies with an extended duration that include antimicrobial and anti-inflammatory agents. The misuse/overuse of antibiotics instigated the emergence of multiple resistant microbial pathogens that require innovative antimicrobial agent/compounds for their fighting [30].

The healing process of wounds comprises six steps: [1] inflammation, [2] cell's migration, [3] angiogenesis, [4] provisional matrix synthesis, [5] collagen deposition, and [6] reepithelization [35]. The Pro-based formulation proved its efficacy in reducing wounded areas, accelerating reepithelization, stimulating cellular proliferative, and decreasing healing time of cutaneous wounds [36, 37].

The current plan involved the extract insect Csn from BSF, to synthesized Ag-NPs using Pro extract, to evaluate their potentiality as antimicrobial candidates against skin pathogens and their capability for accelerating wound healing in rats.

\section{Materials and Methods}

2.1. Chitosan Extraction and Characterization. BSF "Hermetia illucens larvae" were achieved at their fifth instar from the "Experimental insect farm, University of King Abdulaziz, Jeddah, KSA." The majority of BSF oils and proteins were eliminated by oil-press process, and the insects' residues were washed with deionized water (DW) and lyophilized $[3,6]$. The Csn extraction processes involved washing with DW and air drying after each step, which included (1) defatting with 10 folds $(v / w)$ from methanol-chloroform mixture (3: 7 , respectively) and stirring for $4.5 \mathrm{~h}$ at $25 \pm 2^{\circ} \mathrm{C}$; (2) demineralization, using $2 \% \mathrm{HCl}$ solution (12 folds, $v / w$ ) at $25 \pm 2^{\circ} \mathrm{C}$ for $125 \mathrm{~min}$; (3) deproteinization, with 10 folds $(v / w)$ from $\mathrm{NaOH}$ solution $(1.1 \mathrm{M})$ at $50 \pm 2^{\circ} \mathrm{C}$ for $150 \mathrm{~min}$; and lastly, (4) deacetylation, with 15 folds $(v / w)$ from concentrated $\mathrm{NaOH}$ solution $(60 \% w / v)$, at $25 \pm 2^{\circ} \mathrm{C}$ for $35 \mathrm{~min}$ then heating to $110^{\circ} \mathrm{C}$ for $130 \mathrm{~min}$. The resulted Csn was neutralized via repeated washing with DW then lyophilized.

2.2. Propolis Extraction. Collected propolis from apiaries in the Saudi Arabia southwestern regions was employed for extraction, which was conducted with 10 folds $(v / w)$ from $70 \%$ methanol at $27 \pm 2^{\circ} \mathrm{C}$ for $40 \mathrm{~h}$, under shaking $(220 \times \mathrm{g})$. The extracted solution was statically kept at $4^{\circ} \mathrm{C}$ for further $24 \mathrm{~h}$ to precipitate propolis wax [27]. The solution was filtered, centrifuged (to eliminate the precipitated materials), and subjected to vacuum evaporation (Buchi, Flavil, Switzerland) at $42^{\circ} \mathrm{C}$ until dryness. The dried propolis extract (Pro) was redissolved in aqueous ethanol (40\%) to have $10 \%$ concentration $(w / v)$ [38].

2.3. Ag Nanoparticles Synthesis with Propolis Extract. Pro was diluted to $0.1 \%(w / v)$ using $\mathrm{DW}$, and the solution $\mathrm{pH}$ was adjusted to 9.6 using $\mathrm{NaOH}$ solution $(1.0 \mathrm{M})$. The $\mathrm{AgNO}_{3}$ solution $(0.1 \mathrm{M})$ was prepared in DW and $500 \mu \mathrm{L}$ from it was slowly dropped into $10 \mathrm{~mL}$ of Pro solution with speed stirring at $40 \pm 2^{\circ} \mathrm{C}$. The color change to deep brown rapidly initiated (within 5 min of combination), which indicated AgNPs formation [31]. The produced Pro/Ag-NPs solution was then lyophilized and subjected for analysis.

\subsection{Products' Physiognomies Characterization}

2.4.1. UV-Visible (UV-vis) Analysis. The absorbance spectrum of Pro/Ag-NPs solution was spectrophotometrically measured (UV-2450, Shimadzu, Japan), at 200-800 nm range.

2.4.2. FTIR "Fourier-transform infrared spectroscopy" Analysis. The FTIR spectra of produced Pro, insect Csn and their composite were screened using FTIR spectrophotometer (JASCO 4100, Japan), at $450-4000 \mathrm{~cm}^{-1}$ wavenumber range. Homogeneous powdered materials, blended with $\mathrm{KBr}$ (potassium bromide), were examined and their transmittance spectra were plotted.

2.4.3. TEM "Transmission electron microscopy" Imaging. The size, structure, and morphology of the Pro-biosynthesized Ag-NPs were depicted using TEM “JEM-2100, JEOL, Japan”, operated at $180 \mathrm{kV}$ accelerating voltage and after sonication 
of NPs solution in DW for $15 \mathrm{~min}$, mounting onto grids of carbon-coated copper vacuum drying.

2.4.4. XRD "X-Ray Diffraction" Analysis. XRD analysis for Pro-biosynthesized Ag-NPs for purity measurements was made through a diffractometer (XRD-6000, Shimadzu, Japan), applying $\mathrm{Cu}-k_{\alpha}$ radiation $(\lambda=1.541 \AA)$ at $30 \mathrm{~mA}$ and $40 \mathrm{Kv}$ in $10-80^{\circ}$ range of $2 \theta$.

2.4.5. Particle Size (Ps) Distribution and Zeta Potential ( $\zeta)$ Determination. The surface charges (zeta potential, $\zeta$ ) of Pro-biosynthesized Ag-NPs and their Ps distribution were analyzed using zeta plus (Brookhaven, USA).

2.5. Antimicrobial Potentiality Evaluation. The antimimicrobial potentialities of insect Csn, Pro, Pro/Ag-NPs, and their composites were qualitatively/quantitatively evaluated against the challenged skin pathogens, i.e., Candida albicans (ATCC-10231) and Staphylococcus aureus (ATCC-25923), as they are from the most invasive microbial pathogens to skin. The used media for maintaining and challenging microorganisms were Sabouraud Dextrose Broth/Agar (SDB and SDA, Merck, Germany) for the mycotic strain (C. albicans) and Nutrient Broth/Agar (NB and NA, Sigma-Aldrich, St. Louis, MO) for the bacteria strain $S$. aureus, respectively. The microorganisms were propagated and challenged aerobically at $37 \pm 1^{\circ} \mathrm{C}$.

2.5.1. Disc Diffusion. The qualitative assay, measuring appeared inhibition zones (IZ) following disc diffusion method, was conducted via plating microbial cultures onto appropriate solid media and positioning filter paper discs ( $6 \mathrm{~mm}$ diameter) that impregnated with $30 \mu \mathrm{L}$ from each agent solution (with a concentration of $10 \%, w / v)$ onto the surface of inoculated plates. After incubation for 18-24h, the appeared IZ around the discs was measured. Nystatin and Vancomycin were employed as standard antibiotics for comparison, using the same challenging conditions.

2.5.2. MIC "Minimum inhibitory concentration" Assay. The elucidated microdilution technique was followed for assessing the MICs of Csn, Pro, Pro/Ag-NPs, and their composites toward tested skin pathogens [8], using TTC "Triphenyl tetrazolium chloride, Merck, Germany" as an indicator for microbial survival. The successive concentration of 10-200 $\mu \mathrm{g} / \mathrm{mL}$ from each agent in broth media (in 96 well microplates) was fixed and inoculated with $\sim 10^{7} \mathrm{CFU} / \mathrm{mL}$ from microbial cells, with the addition of $0.5 \%$ TTC. Samples from the colorless wells were subsequently plated onto agar media and incubated to verify the microbicidal action. The MICs were specified as the minimum concentration of a particular agent that prohibited microbial survival in microplates and on agar plates.

2.5.3. SEM "Scanning electron microscopy" Imaging. The SEM (Hitachi S-500, Japan) micrographs were captured for the exposed microbial cells, C. albicans and $S$. aureus, to Pro/Ag-NPs (at a concentration of $45.0 \mu \mathrm{g} / \mathrm{mL}$ in broth media), to elucidate the structural alterations in cells after treatment for 0,4 , and $8 \mathrm{~h}$.
2.6. Wound Healing Potentiality of Composited Materials. Young Wistar healthy rats (average weight between 141 and $164 \mathrm{~g}$ ) were individually housed under maintained conditions " $25 \pm 2^{\circ} \mathrm{C} ; 12 \mathrm{~h}$ of light-dark cycle; $65 \pm 3 \%$ relative humidity" in polyethylene clean cages. Animal's handling and practical experiments were implemented following the guidelines of "Saudi Ethical Committee for the care and use of laboratory animals" with the aid of two veterinarian technicians. The experiment period lasted for 14 days, with rats feeding on a customary pellet diet and free water access. After anesthesia induction via ketamine intramuscular injection (100 mg/kg body weight), wounds with semicircular areas of $\sim 65 \mathrm{~mm}^{2}$ were made on shaved rats' thoracic area. From the wounding day (day 0), the experimented composite $[\mathrm{Csn}(1 \%)+\operatorname{Pro} / \mathrm{Ag}-\mathrm{NPs}(0.1 \%)$, dissolved in DW] was topically smeared every $12 \mathrm{~h}$ until complete epithelization (the Ag-NPs color intense became lesser after conjugating with Csn and Pro solutions). Wounds were digitally photographed daily, after precise cleansing of the wounded area with sterile saline solution $(0.9 \% \mathrm{NaOH})$; the reductions and manifestation of wounded areas were appraised from the captured photographs.

2.7. Statistical Analysis. Trials were mostly triplicated; their means and SD "standard deviation" were computed (by Microsoft Excel 2016). T-test and One-way ANOVA were applied for statistical significance computation using the MedCalc software (V. 18.2.1, Mariakerke, Belgium) at $p \leq 0.05$.

\section{Results and Discussion}

Csn was promisingly extracted from BSF larvae with a final yield of $1.56 \%$. Table 1 illustrated the obtained yields after each process in Csn extraction. The physiochemical attributes of BSF-Csn were the DD of $91.3 \%$, a MW of 88.600 Dalton. Produced Csn had $97.8 \%$ solubility in $1 \%$ AC "acetic acid solution", without heating.

The BSF-derived chitin and Csn were reported as novel sources for these valuable compounds [4]; BSF requires specific extraction processes, e.g., defatting, due to their high contents of lipids [5]. The fifth instar in BSF larvae development was highly advised for Csn extraction, as after this stage, more pigments and melanin are found in covalently binding with chitin, which leads to poor color attributes for the product $[4,7]$.

The BSF-Csn spectrum (Figure 1-Csn) indicated typical bonds of standard Csn, illustrated in literature. The main designative bands were detected at $3456 \mathrm{~cm}^{-1}\left(\mathrm{NH}_{2}\right), 2311$ $\mathrm{cm}^{-1}\left(\mathrm{C}-\mathrm{H}\right.$ ), $1635 \mathrm{~cm}^{-1}$ (amide I, $\mathrm{C}=\mathrm{O}$ ), $1402 \mathrm{~cm}^{-1}$ (amide III, C-N), $1112 \mathrm{~cm}^{-1}(\mathrm{C}-\mathrm{O})$, and $896 \mathrm{~cm}^{-1}(\mathrm{C}-\mathrm{H})$, receptively. Additionally, the $\mathrm{C}-\mathrm{H}$ stretching vibrations and $\mathrm{C}-\mathrm{O}$ bending were also observed at $2879 \mathrm{~cm}^{-1}$ and 1069 $\mathrm{cm}^{-1}$, respectively. The detected designative bands in BSFCsn here are in accordance with former modern investigations concerned insect Csn extraction and characterizations from different types included mealworm, cicada slough, beetles "Calosoma rugosa," desert locust "Schistocerca gregaria," honey bee "Apis mellifera," grasshopper, silkworm chrysalis, and BSF $[2,3,7]$. 
TABLE 1: The obtained yields throughout insect chitosan extraction.

\begin{tabular}{lccc}
\hline $\begin{array}{l}\text { Extraction } \\
\text { process }\end{array}$ & $\begin{array}{c}\text { Weight } \\
\text { after } \\
\text { process }^{*}\end{array}$ & $\begin{array}{c}\text { Yield from } \\
\text { previous row } \\
\text { material (\%) }\end{array}$ & $\begin{array}{c}\text { Yield from } \\
\text { initial row } \\
\text { material }^{*}(\%)\end{array}$ \\
\hline Oil press & 43.2 & 8.64 & 8.64 \\
Defatting & 41.6 & 96.43 & 8.32 \\
Demineralization & 23.8 & 57.21 & 4.76 \\
Deproteinization & 11.6 & 48.57 & 2.32 \\
Deacetylation & 7.8 & 67.42 & 1.56 \\
\hline
\end{tabular}

* The initial raw material weight was $500 \mathrm{~g}$ of complete insects.

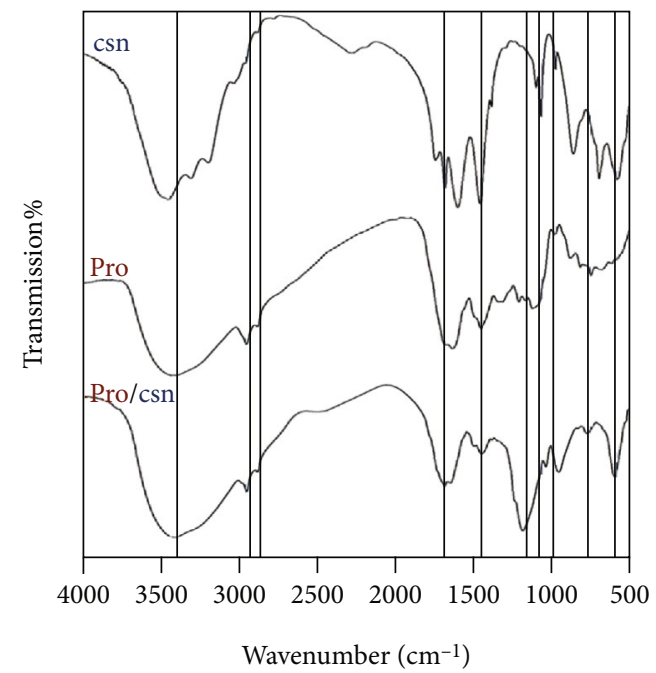

FIgURe 1: FTIR spectra of insect chitosan (Csn), propolis extract (Pro), and their composite (Pro/Csn).

For Pro (Figure 1-Pro), $889 \mathrm{~cm}-1$ (C-H bonds of phenolic rings), 1151 and $1282 \mathrm{~cm}-1$ (stretched $\mathrm{C}-\mathrm{O}$ and $\mathrm{C}-\mathrm{N}$ bond of amino acids aromatic), $1621 \mathrm{~cm}-1$ ( $-\mathrm{COO}^{-}$carboxylate anion), 1654 and $2971 \mathrm{~cm}-1$ ( $\mathrm{C}=\mathrm{O}$ of flavonoids), $2924 \mathrm{~cm}-1$ (stretched $\mathrm{CH}_{2}$ vibrations of phenolics), and broadband around $3432 \mathrm{~cm}-1$ (Free N-H) $[33,39,40]$.

Regarding the Csn/Pro composite spectrum (Figure 1Pro/Csn), the interactions between Csn and Pro were evidently confirmed from appeared bands in the composite that belong to both constituting agents (indicated with vertical blue lines in figure).

The Ag-NPs were efficaciously synthesized using Pro extract, as evinced from their color changing from bale white to deep brown, after interaction with Pro solution (Figure 2upper part). The observable color change after mixing of Pro and $\mathrm{AgNO}_{3}$ solutions advocated the $\mathrm{Ag}^{+}$reduction to NP form that have free electrons and SPR "surface plasmon resonance" excitation absorption [41].

The UV-vis absorption spectrum of Pro-synthesized AgNPs revealed a distinctive apparent peak at $422 \mathrm{~nm}$ (Figure 2lower part), which belong to the designative SPR for biogenic synthesized Ag-NPs (within 220-425 nm), performed formerly using varied plant extracts $[19,22,25]$. They reported also that SPR absorption band frequency/width are princi-

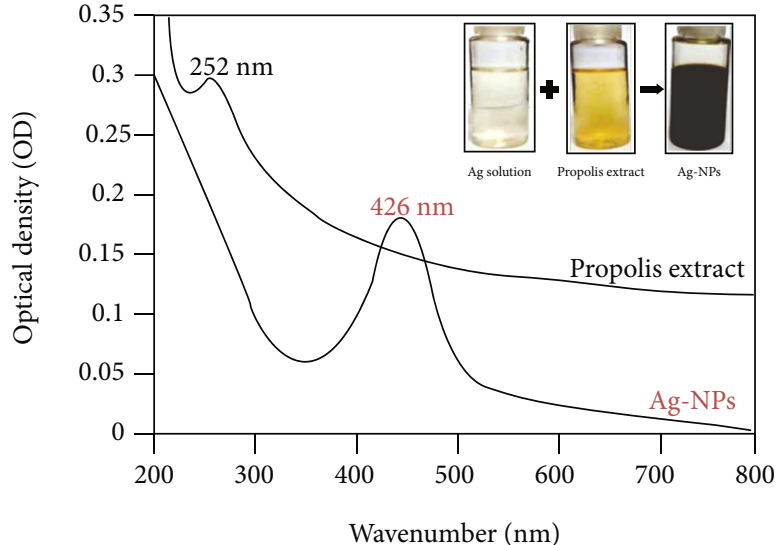

Figure 2: Visual guise and optical density of propolis extract and propolis-synthesized Ag-NPs.

pally based on NPs size, shape, dielectric constants "the composition of the particles and surrounding medium" [41]. The detection of single SPR band frequently indicates the NPs spherical shape, while $\geq$ two SPR bands are mostly corresponding to anisotropic particles [42]. As the UV-vis spectroscopy is frequently distinguishing size-controlled NPs and their shapes in aqueous solutions, the current pattern could indicate the capability and efficiency of Pro solution to reduce Ag to Ag-NPs and advocate the phytosynthesis of NPs [31].

The structural analysis of Pro-synthesized Ag-NPs revealed that NPs were well-distributed and spherically shaped (Figure 3(a)). The NPs diameter size ranged from 3.89 to $24.12 \mathrm{~nm}$, with a mean diameter of $8.73 \mathrm{~nm}$ and median diameter of $8.42 \mathrm{~nm}$. Additionally, the Prosynthesized Ag-NPs had a $\zeta$ value of $-21.34 \mathrm{mV}$.

The XRD analysis of phytosynthesized Ag-NPs disclosed clear peaks' existence at $2 \theta=38.13^{\circ}, 44.28^{\circ}, 64.61^{\circ}, 77.42^{\circ}$, and $81.84^{\circ}$, which are accredited to (111), (200), (220), (311), and (222) reflections of fcc "face-centered cubic", respectively, indicating metallic Ag structure (Figure 3(b)). These attributes were formerly indicated for the biogenic synthesized Ag-NPs, especially using plants' extracts and phytochemicals [20, 22, 26, 43].

The surface of Ag-NPs was suggested as frequently carriers for negative charges, when dispersed in medium; these negative values reinforce the NPs repulsion and elevated stability [26].

The XRD pattern (Figure 3(b)) evidently exhibited the Ag-NPs crystalline nature, as expected from these biosynthesized NPs [22]. As the appeared peaks markedly indicate the NPs cubic crystallinity [20], Pro proved its capability as a promising candidate (from waste materials) for efficient Ag-NPs development.

The antimicrobial potentialities of insect Csn, Pro, synthesized Ag-NPs with Pro, and their composite against skin pathogens (S. aureus and C. albicans), comparing with customary (vancomycin and nystatin), are demonstrated in Table 2. The microbial inhibitory activities were observable for all examined agents; the most forceful treatment was the combined Csn+Pro+Ag-NPs, as it exhibited the least MIC 


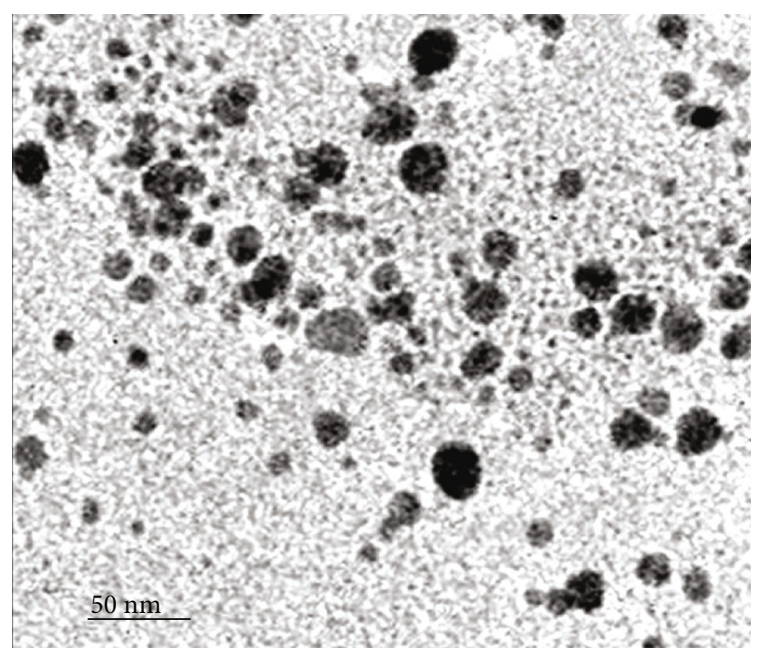

(a)

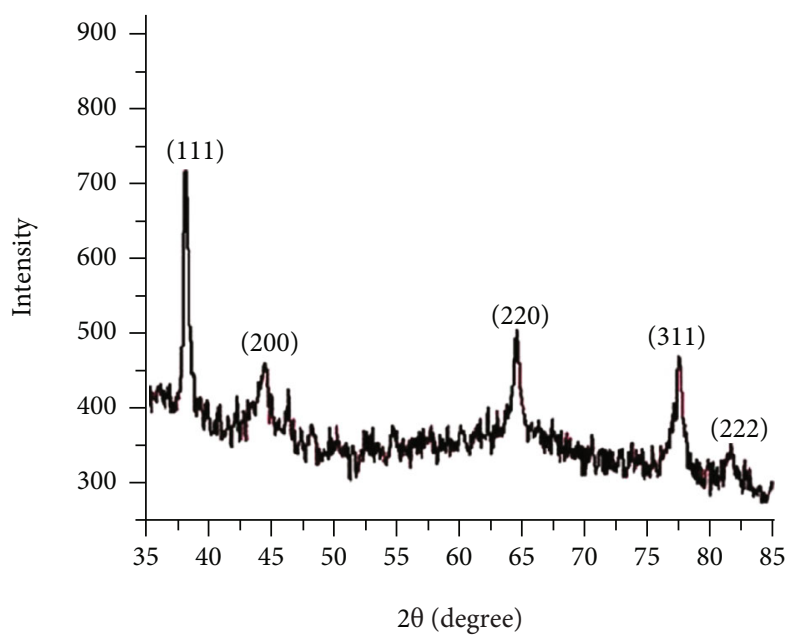

(b)

FIGURE 3: TEM depiction (a) and XRD analysis (b) of phytosynthesized Ag-NPs with propolis extract.

TABle 2: Antimicrobial potentialities* of insect chitosan, propolis extract, synthesized Ag-NPs with propolis extract, and their composite against skin microbial pathogens.

\begin{tabular}{|c|c|c|c|c|}
\hline \multirow{2}{*}{ Agents } & \multicolumn{2}{|c|}{ Staphylococcus aureus } & \multicolumn{2}{|c|}{ Candida albicans } \\
\hline & $\mathrm{IZ}(\mathrm{mm})^{* *}$ & $\mathrm{MIC}(\mu \mathrm{g} / \mathrm{mL})$ & $\mathrm{IZ}(\mathrm{mm})$ & $\mathrm{MIC}(\mu \mathrm{g} / \mathrm{mL})$ \\
\hline Chitosan & $14.6 \pm 2.1^{\mathrm{a}}$ & 85.0 & $9.9 \pm 1.8^{\mathrm{a}}$ & 92.5 \\
\hline Propolis extract & $17.3 \pm 3.3^{\mathrm{a}}$ & 75.0 & $11.7 \pm 2.1^{\mathrm{a}}$ & 85.0 \\
\hline Propolis/Ag-NPs & $24.6 \pm 3.2^{\mathrm{b}}$ & 37.5 & $19.1 \pm 2.5^{\mathrm{b}}$ & 45.0 \\
\hline Chitosan/Propolis/Ag-NPs & $26.3 \pm 4.8^{\mathrm{b}}$ & 35.0 & $23.4 \pm 2.2^{\mathrm{c}}$ & 45.0 \\
\hline Vancomycin & $23.5 \pm 3.7^{b}$ & 40.0 & ND & ND \\
\hline Nystatin & ND & ND & $19.8 \pm 3.3^{\mathrm{b}}$ & 52.5 \\
\hline
\end{tabular}

*IZ: appeared inhibition zones included diameter of assay disc; MIC: "minimum inhibitory concentrations." ** Within one column, dissimilar letters (superscript) indicate significant differences.

values and the largest ZOI diameters toward both microorganisms. The effect of Ag-NPs was very noticeable for inhibiting skin pathogens; the antibacterial actions (against $S$. aureus) of examined agents were more effectual than their antimycotic actions (against C. albicans).

The antimicrobial powers of phytosynthesized Ag-NPs were proved toward numerous pathogens; the assumed mechanisms depended on the NPs ability to attach and penetrate into microbial cells, disturb membrane permeability and interrupt respiration functions, disrupt DNA replication, and ATP production [17, 20, 22, 44, 45].

The observation of SEM micrographs of treated microorganisms with Pro-synthesized Ag-NPs appointed the consequences of NPs treatment on microbial topography and structure (Figure 4). The control cells in the initiation of exposure, i.e., C. albicans (Figure 4-C0) and S. aureus (Figure 4-S0), appeared with healthy normal structures and utterly smooth intact membranes. After $4 \mathrm{~h}$ of exposure (Figure 4-C4 and S4), the interactions between NPs and microbial cells' walls were noticeable, with the appearance of partial cell lysis, especially in $S$. aureus cells. The extension of NPs exposure to $8 \mathrm{~h}$ lead to complete cell lysis in S. aureus cells (Figure 4-S8) that released their interior contents and exploded, whereas the $C$. albicans cells were obviously deformed and many lysis signs were appeared in this stage (Figure 4-C0).

The attachments of Ag-NPs to microbial surfaces are mostly due to electrostatic attraction [46]; this nanoparticulate attribute was proposed as the leading basis for NPs bactericidal action [47]. Due to high electrostatic affinity and attractions of $\mathrm{Ag}^{+}$ions towards sulfur proteins in cells' surface, the NPs can frequently adhere to cells' cytoplasm and walls, upsurge membranes' permeability and elasticity, which derive microbial casings' disruptions $[23,24]$. Once the $\mathrm{Ag}^{+}$ ions get uptaken inside microbial cells, the deactivations of respiratory enzymes are occurred, leading to elevated ROS production and ATP release interruption [17]; these ROSs are aggressive factors for enforcing cellular membranes' disruption and DNA distortions. Furthermore, via denaturing the ribosomal cytoplasm components, $\mathrm{Ag}^{+}$ions could competently hinder cellular protein synthesis [48]. Conversely, the biosynthesized Ag-NPs were reported to have elevated biocompatibility and minor toxicity toward mammalian natural cells, e.g., RBCs "red blood cells," PBMCs “peripheral 


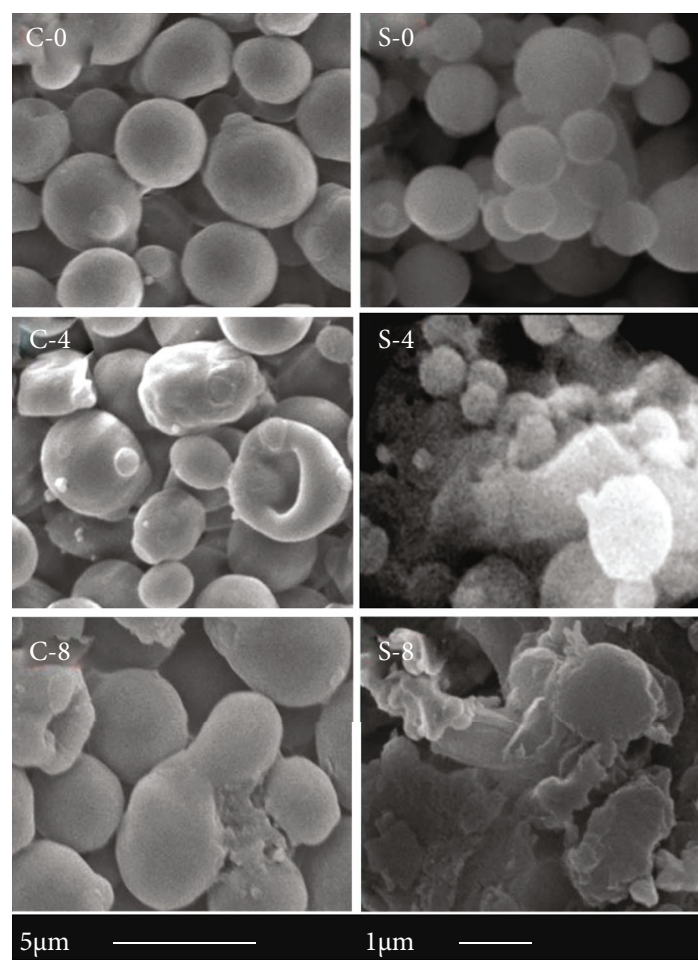

Figure 4: SEM micrographs of exposed Candida albicans (C) and Staphylococcus aureus (S) cells to synthesized Ag nanoparticles with propolis extract for 0,4 , and $8 \mathrm{~h}$.

blood mononuclear cells," and HEK "human embryonic kidney," which advocated their practical biomedical applications $[23,44,45]$.

Ag-NPs themselves can eradicate exposed microbes; the cumulative NPs trigger cell's membranes denaturation and can permeate through these membranes to modify their structural arrangements [24]. The interior cell's organelles could be also ruptured after membranes' denaturation, and this promotes cell lysis/death [49]. The shape of Ag-NPs was demonstrated for influencing their bactericidal power [50], and the spherical shapes with tinier sizes provide more reactive contact facets that strengthen NPs activity [21].

The skin wounds' treatment with Csn/Pro/Ag-NPs composite promoted faster healing of wounded rats' skin during 14 days of local treatment (Figure 5). For the untreated group (Figure 5-control), no complete healing was observed after 14 days, and the mean wound size reduced from $65.4 \mathrm{~mm}^{2}$ to $59.8,41.3,28.5,22.7,18.2$, and $6.84 \mathrm{~mm}^{2}$ after $4,6,8,10$, 12 , and 14 days, respectively. The healing signs appeared much faster in the treated group with Csn/Pro/Ag-NPs composite (Figure 5-treated); the wounded parts became mostly healed after 12 days of treatment.

The composite-treated wounds had no signs of microbial contamination, pus formation, or bleeding throughout treatment, whereas untreated wounds exhibited remarkable inflammation and infection signs. By the $4^{\text {th }}$ day onwards, Csn/Pro/Ag-NPs-treated wounds showed notable wound size reduction and distinguished closure, which were further progressed in the subsequent days of treatment.

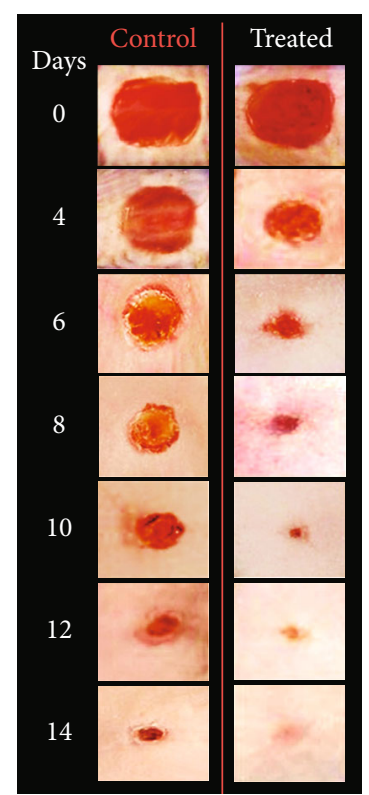

FIgURE 5: Consequence of treatment rats' skin wounds with chitosan/propolis extract/Ag-NPs composite (treated) on the healing rate of wounds during 14 days, compared to untreated (control) wounds.

The selection of $S$. aureus and C. albicans as models for skin pathogens based on their hazardous infections and contamination of epidermal wounds/burns, which resulted in many complications and disorders of infected parts [51]. Additionally, the inclusion of both bacterial and fungal skin pathogens in challenging trials can give more reliability and trustworthiness of the effectiveness and applicability of examined agents. Both $S$. aureus and C. albicans can possess the antimicrobial resistance, which require innovative microbicidal agents to overcome their skin wounds' infections $[52,53]$. The combined presence of the two pathogens could increase their biofilm formation and antimicrobial resistance [54].

$S$. aureus is from the extremely dangerous pathogenic microorganism that threatens humans; the bacteria habitually located in skin and mucus membranes and could enter the bloodstreams through wounds and skin scratches [55]. In numerous skin and wound infections' studies, involving colonization and resistance characteristics, $S$. aureus was focused and reported to repeatedly cause severe bloodstream infections [51]. C. albicans was categorized among the hazardous fungal infections in diabetic ulcers and skin wounds, which remarkably delayed their healing $[56,57]$.

The usage of natural derivatives for wound treatments, as alternatives to chemotherapy, attained great concerns to manage skin infections and promote its regeneration [34]. Pro-based formulations were proposed as effectual treatments to accelerate the natural reorganization of injured tissues, through augmenting keratinocyte proliferation [58]. Even diabetic wounds were effectually healed with Pro via decrement the levels of MMPs "matrix metalloproteinases" and proinflammatory cytokines, enhancing the deposition of collagen I and VEGF "vascular endothelial growth factor" 
in injured skin $[28,59]$, thus hastening the healing development. The healthy skin could too benefit from Pro protective properties, e.g., its persuasive anti-inflammatory, antimicrobial, photoprotective, and antioxidants activities [37, 60].

The wound size reduction and their closure are principally resulting from the antimicrobial and antiinflammatory actions of the composite components, i.e., Csn, Pro, and Ag-NPs. The microbicidal activity of Ag-NPs could prevent wound microbial contamination, which consequently enabled tissue integrity restoring and resulted in adequate repairing of injured sites [22]. The Ag-NP potential role in rapid wound healing was reported to have dosedependent manner with a healthier cosmetic appearance [61]. Besides, by their microbicidal potentials, Ag-NPs displayed positive consequences for deceasing wound inflammation through diminishing mast cell and lymphocyte infiltration and fibrogenic cytokines amendments [62]. Likewise, the potentiality of Ag-NPs in epidermal reepithelialization and dermal contraction throughout the healing process was the supposed factors for reproduction promotion, keratinocytes migration increment, and fibroblasts differentiation into myofibroblasts $[18,44,61,63]$.

Chitin and Csn were supposed to enhance the healing process in wounded skins. The multiple of mono-subunit ( $\mathrm{N}$-acetyl glucosamine), in these polymers' composition, is an imperative constituent in dermal tissue and has a vital necessity for repairing scar tissues $[10,64]$. The Csn surface has numerous free amine groups, which can conjoin with blood acidic groups and enhance their coagulation $[35,65$, 66]. Csn molecules (by their high positive charge) can effectively promote cells' growth and assist thrombosis/blood coagulation $[12,63,67,68]$, which greatly foster damaged tissue repairing.

\section{Conclusion}

The biosynthesis of Ag-NPs from Pro and extraction of insect Csn from BSF were promisingly attained in the current work. Csn was extracted from BSF "black soldier fly as an unconventional source for this polymer. The Probiosynthesis of Ag-NPs applied simple, direct, and ecofriendly protocol that generated the desired size, shape, and distribution of nanoparticles. The composite of these agents (Pro-synthesized Ag-NPs and Csn) exhibited powerful antimicrobial potentialities against skin pathogens (C. albicans and $S$. aureus) and high capability for fast wound healing, without the emergence of infection or inflammation signs, which strongly advocate their applications for skin protection, disinfection, and regeneration.

\section{Data Availability}

The datasets generated and/or analyzed during the current study are available from the corresponding author on reasonable request.

\section{Conflicts of Interest}

The author declares that they have no conflicts of interest.

\section{References}

[1] S. Kou, L. Peters, and M. Mucalo, "Chitosan: a review of sources and preparation methods," International Journal of Biological Macromolecules, vol. 169, pp. 85-94, 2021.

[2] Q. Luo, Y. Wang, Q. Han et al., "Comparison of the physicochemical, rheological, and morphologic properties of chitosan from four insects," Carbohydrate Polymers, vol. 209, pp. 266275, 2019.

[3] T. Hahn, A. Roth, R. Ji, E. Schmitt, and S. Zibek, "Chitosan production with larval exoskeletons derived from the insect protein production," Journal of Biotechnology, vol. 310, pp. 62-67, 2020.

[4] A. Khayrova, S. Lopatin, and V. Varlamov, "Black soldier fly Hermetia illucens as a novel source of chitin and chitosan," International Journal of Sciences, vol. 8, no. 4, pp. 81-86, 2019.

[5] A. Mertenat, S. Diener, and C. Zurbrügg, "Black Soldier Fly biowaste treatment - assessment of global warming potential," Waste Management, vol. 84, pp. 173-181, 2019.

[6] N. H. Marei, E. A. El-Samie, T. Salah, G. R. Saad, and A. H. Elwahy, "Isolation and characterization of chitosan from different local insects in Egypt," International Journal of Biological Macromolecules, vol. 82, pp. 871-877, 2016.

[7] N. Marei, A. H. Elwahy, T. A. Salah, Y. El Sherif, and E. A. ElSamie, "Enhanced antibacterial activity of Egyptian local insects' chitosan-based nanoparticles loaded with ciprofloxacin-HCl," International Journal of Biological Macromolecules, vol. 126, pp. 262-272, 2019.

[8] A. A. Tayel, S. Moussa, W. F. El-Tras, D. Knittel, K. Opwis, and E. Schollmeyer, "Anticandidal action of fungal chitosan against Candida albicans," International Journal of Biological Macromolecules, vol. 47, no. 4, pp. 454-457, 2010.

[9] A. A. Tayel, M. M. Gharieb, H. R. Zaki, and N. M. Elguindy, "Bio-clarification of water from heavy metals and microbial effluence using fungal chitosan," International Journal of Biological Macromolecules, vol. 83, pp. 277-281, 2016.

[10] V. K. H. Bui, D. Park, and Y. C. Lee, "Chitosan combined with $\mathrm{ZnO}, \mathrm{TiO} 2$ and $\mathrm{Ag}$ nanoparticles for antimicrobial wound healing applications: a mini review of the research trends," Polymers, vol. 9, no. 12, p. 21, 2017.

[11] S. Kim, "Competitive biological activities of chitosan and its derivatives: antimicrobial, antioxidant, anticancer, and antiinflammatory activities," International Journal of Polymer Science, vol. 2018, Article ID 1708172, 13 pages, 2018.

[12] A. Moeini, P. Pedram, P. Makvandi, M. Malinconico, and G. G. d'Ayala, "Wound healing and antimicrobial effect of active secondary metabolites in chitosan-based wound dressings: a review," Carbohydrate Polymers, vol. 233, p. 115839, 2020.

[13] P. M. Matei, P. Martín-Ramos, M. S.-B. S. Hernández-Navarro et al., "Synthesis of chitosan oligomers/propolis/silver nanoparticles composite systems and study of their activity against Diplodia seriata," International Journal of Polymer Science, vol. 2015, Article ID 864729, 11 pages, 2015.

[14] A. I. Alalawy, H. A. El Rabey, F. M. Almutairi et al., "Effectual anticancer potentiality of loaded bee venom onto fungal chitosan nanoparticles," International Journal of Polymer Science, vol. 2020, Article ID 2785304, 9 pages, 2020.

[15] L. A. Kolahalam, I. K. Viswanath, B. S. Diwakar, B. Govindh, V. Reddy, and Y. L. N. Murthy, "Review on nanomaterials: synthesis and applications," Materials Today: Proceedings, vol. 18, pp. 2182-2190, 2019. 
[16] R. G. Saratale, I. Karuppusamy, G. D. Saratale et al., “A comprehensive review on green nanomaterials using biological systems: recent perception and their future applications," Colloids and Surfaces B: Biointerfaces, vol. 170, pp. 20-35, 2018.

[17] C. A. Das, V. G. Kumar, T. S. Dhas et al., "Antibacterial activity of silver nanoparticles (biosynthesis): a short review on recent advances," Biocatalysis and Agricultural Biotechnology, vol. 18, p. 101593, 2020.

[18] T. Gunasekaran, T. Nigusse, and M. D. Dhanaraju, "Silver nanoparticles as real topical bullets for wound healing," Journal of the American College of Clinical Wound Specialists, vol. 3, no. 4, pp. 82-96, 2012.

[19] P. Logeswari, S. Silambarasan, and J. Abraham, "Ecofriendly synthesis of silver nanoparticles from commercially available plant powders and their antibacterial properties," Scientia Iranica. F, vol. 20, pp. 1049-1054, 2013.

[20] S. Bhakya, S. Muthukrishnan, M. Sukumaran, and M. Muthukumar, "Biogenic synthesis of silver nanoparticles and their antioxidant and antibacterial activity," Applied Nanoscience., vol. 6, no. 5, pp. 755-766, 2016.

[21] V. E. dos Santos Junior, A. G. R. Targino, M. A. P. Flores et al., "Antimicrobial activity of silver nanoparticle colloids of different sizes and shapes against Streptococcus mutans," Research on Chemical Intermediates, vol. 43, no. 10, pp. 5889-5899, 2017.

[22] H. S. Al-Shmgani, W. H. Mohammed, G. M. Sulaiman, and A. H. Saadoon, "Biosynthesis of silver nanoparticles from Catharanthus roseus leaf extract and assessing their antioxidant, antimicrobial, and wound-healing activities," Artificial cells, Nanomedicine, and Biotechnology, vol. 45, no. 6, pp. 1234-1240, 2017.

[23] S. Khorrami, A. Zarrabi, M. Khaleghi, M. Danaei, and M. Mozafari, "Selective cytotoxicity of green synthesized silver nanoparticles against the MCF-7 tumor cell line and their enhanced antioxidant and antimicrobial properties," International Journal of Nanomedicine, vol. Volume 13, pp. 80138024, 2018.

[24] S. A. Ahmad, S. S. Das, A. Khatoon et al., "Bactericidal activity of silver nanoparticles: a mechanistic review," Materials Science for Energy Technologies, vol. 3, pp. 756-769, 2020.

[25] B. S. Maria, A. Devadiga, V. S. Kodialbail, and M. B. Saidutta, "Synthesis of silver nanoparticles using medicinal Zizyphus xylopyrus bark extract," Applied Nanoscience, vol. 5, no. 6, pp. 755-762, 2015.

[26] K. Anandalakshmi, J. Venugobal, and V. Ramasamy, "Characterization of silver nanoparticles by green synthesis method using Pedalium murex leaf extract and their antibacterial activity," Applied Nanoscience, vol. 6, no. 3, pp. 399-408, 2016.

[27] Y. Elnakady, A. Rushdi, R. Franke et al., "Characteristics, chemical compositions and biological activities of propolis from Al-Bahah, Saudi Arabia," Scientific Reports, vol. 7, no. 1, p. 41453, 2017.

[28] W. N. Hozzein, G. Badr, A. A. Al Ghamdi, A. Sayed, N. S. AlWaili, and O. Garraud, "Topical application of propolis enhances cutaneous wound healing by promoting TGFbeta/Smad-mediated collagen production in a streptozotocininduced type I diabetic mouse model," Cellular Physiology and Biochemistry, vol. 37, no. 3, pp. 940-954, 2015.

[29] I. Al-Ani, S. Zimmermann, J. Reichling, and M. Wink, “Antimicrobial activities of European propolis collected from various geographic origins alone and in combination with antibiotics," Medicines, vol. 5, no. 1, p. 2, 2018.
[30] E. Rojczyk, A. Klama-Baryła, W. Łabuś, K. Wilemska-Kucharzewska, and M. Kucharzewski, "Historical and modern research on propolis and its application in wound healing and other fields of medicine and contributions by Polish studies," Journal of Ethnopharmacology, vol. 262, p. 113159, 2020.

[31] N. Roy, S. Mondal, R. A. Laskar, S. Basu, D. Mandal, and N. A. Begum, "Biogenic synthesis of $\mathrm{Au}$ and Ag nanoparticles by Indian propolis and its constituents," Colloids and Surfaces B: Biointerfaces, vol. 76, no. 1, pp. 317-325, 2010.

[32] R. Shubharani, M. Mahesh, and V. Yogananda Murthy, "Biosynthesis and characterization, antioxidant and antimicrobial activities of selenium nanoparticles from ethanol extract of Bee Propolis," Journal of Nanomedicine \& Nanotechnology, vol. 10, no. 1, p. 522, 2019.

[33] C. E. A. Botteon, L. B. Silva, G. V. Ccana-Ccapatinta et al., "Biosynthesis and characterization of gold nanoparticles using Brazilian red propolis and evaluation of its antimicrobial and anticancer activities," Scientific Reports, vol. 11, no. 1, pp. 116, 2021.

[34] M. F. Medellin-Luna, J. E. Castaneda-Delgado, V. Y. MartinezBalderas, and A. R. Cervantes-Villagrana, "Medicinal plant extracts and their use as wound closure inducing agents," Journal of Medicinal Food, vol. 22, no. 5, pp. 435-443, 2019.

[35] D. Archana, J. Dutta, and P. K. Dutta, "Evaluation of chitosan nano dressing for wound healing: characterization, in vitro and in vivo studies," International Journal of Biological Macromolecules, vol. 57, pp. 193-203, 2013.

[36] A. M. Abu-Seida, "Effect of propolis on experimental cutaneous wound healing in dogs," Veterinary Medicine International, vol. 2015, Article ID 672643, 4 pages, 2015.

[37] A. A. Zohery, S. M. Meshri, M. I. Madi, S. S. Abd El Rehim, and Z. M. Nour, "Egyptian propolis compared to nanohydroxyapatite graft in the treatment of Class II furcation defects in dogs," Journal of Periodontology, vol. 89, no. 11, pp. 13401350, 2018.

[38] A. A. Tayel and W. F. El-Tras, "Plant extracts as potent biopreservatives for salmonella typhimurium control and quality enhancement in ground beef," Journal of Food Safety, vol. 32, no. 1, pp. 115-121, 2012.

[39] A. A. Righi, G. Negri, and A. Salatino, "Comparative chemistry of propolis from eight Brazilian localities," Evidence-based Complementary and Alternative Medicine, vol. 2013, Article ID 267878, 14 pages, 2013.

[40] N. Ibrahim, A. J. Zakaria, Z. Ismail, Y. Ahmad, and K. S. Mohd, "Application of GCMS and FTIR fingerprinting in discriminating two species of Malaysian stingless bees propolis," International Journal of Engineering and Technology, vol. 7, pp. 106-112, 2018.

[41] B. J. Wiley, S. H. Im, Z. Y. Li, J. McLellanm, A. Siekkinen, and Y. Xia, "Maneuvering the surface plasmon resonance of silver nanostructures through shape-controlled synthesis," Journal of Physical Chemistry B, vol. 110, no. 32, pp. 15666-15675, 2006.

[42] C. Udayasoorian, K. Vinoth Kumar, and R. M. Jayabalarishnan, "Extracellular synthesis of silver nanoparticles using leaf extract of Cassia auriculata," Digest Journal of Nanomaterials and Biostructures, vol. 6, pp. 279-283, 2011.

[43] A. Shah, S. Haq, W. Rehman, M. Waseem, S. Shoukat, and M. U. Rehman, "Photocatalytic and antibacterial activities of Paeonia emodi mediated silver oxide nanoparticles," Materials Research Express, vol. 6, no. 4, article 045045, 2019. 
[44] M. Oves, M. Aslam, M. A. Rauf et al., "Antimicrobial and anticancer activities of silver nanoparticles synthesized from the root hair extract of Phoenix dactylifera," Materials Science and Engineering: C, vol. 89, pp. 429-443, 2018.

[45] M. Oves, M. A. Rauf, A. Hussain et al., "Antibacterial silver nanomaterial synthesis from Mesoflavibacter zeaxanthinifaciens and targeting biofilm formation," Frontiers in Pharmacology, vol. 10, p. 801, 2019.

[46] Y. W. Cao, R. Jin, and C. A. Mirkin, "DNA-modified coreshell Ag/Au nanoparticles," Journal of the American Chemical Society, vol. 123, no. 32, pp. 7961-7962, 2001.

[47] E. D. Matthew, N. M. Schaeublin, K. E. Farrington, S. M. Hussain, and G. R. Johnson, "Lysozyme catalyzes the formation of antimicrobial silver nanoparticles," ACS Nano, vol. 3, pp. 984994, 2009.

[48] V. Pareek, R. Gupta, and J. Panwar, "Do physico-chemical properties of silver nanoparticles decide their interaction with biological media and bactericidal action? A review," Materials Science and Engineering: C, vol. 90, pp. 739-749, 2018.

[49] C. Liao, Y. Li, and S. C. Tjong, "Bactericidal and cytotoxic properties of silver nanoparticles," International Journal of Molecular Sciences, vol. 20, no. 2, p. 449, 2019.

[50] X. Hong, J. Wen, X. Xiong, and Y. Hu, "Shape effect on the antibacterial activity of silver nanoparticles synthesized via a microwave-assisted method," Environmental Science and Pollution Research, vol. 23, no. 5, pp. 4489-4497, 2016.

[51] A. L. Byrd, Y. Belkaid, and J. A. Segre, "The human skin microbiome," Nature Reviews Microbiology, vol. 16, no. 3, pp. 143155, 2018.

[52] R. A. Proctor, "Challenges for a universal Staphylococcus aureus vaccine," Clinical Infectious Diseases, vol. 54, no. 8, pp. 1179-1186, 2012.

[53] L. Kalan and E. A. Grice, "Fungi in the wound microbiome," Advances in Wound Care, vol. 7, no. 7, pp. 247-255, 2018.

[54] E. F. Kong, C. Tsui, S. Kucharíková, D. Andes, P. Van Dijck, and M. A. Jabra-Rizk, "Commensal protection of Staphylococcus aureus against antimicrobials by Candida albicans biofilm matrix," MBio, vol. 7, no. 5, 2016.

[55] J. P. Rasigade and F. Vandenesch, "Staphylococcus aureus: a pathogen with still unresolved issues," Infection, Genetics and Evolution, vol. 21, pp. 510-514, 2014.

[56] L. Kalan, M. Loesche, B. P. Hodkinson et al., "Redefining the chronic-wound microbiome: fungal communities are prevalent, dynamic, and associated with delayed healing," MBio, vol. 7, no. 5, 2016.

[57] A. Kühbacher, A. Burger-Kentischer, and S. Rupp, "Interaction of Candida species with the skin," Microorganisms, vol. 5 , no. 2 , p. 32, 2017

[58] E. Sehn, L. Hernandes, S. L. Franco, C. C. Goncalves, and M. L. Baesso, "Dynamics of reepithelialisation and penetration rate of a bee propolis formulation during cutaneous wounds healing," Analytica Chimica Acta, vol. 635, no. 1, pp. 115-120, 2009.

[59] D. S. Ernawati and A. Puspa, "Expression of vascular endothelial growth factor and matrix metalloproteinase-9 in Apis mellifera Lawang propolis extract gel-treated traumatic ulcers in diabetic rats," Veterinary World, vol. 11, no. 3, pp. 304-309, 2018.

[60] N. Saewan and A. Jimtaisong, "Natural products as photoprotection," Journal of Cosmetic Dermatology, vol. 14, no. 1, pp. 47-63, 2015.
[61] P. Y. Lee, C. M. Ho, and V. C. H. Lui, "Silver nanoparticles mediate differential responses in keratinocytes and fibroblasts during skin wound healing," Chem Med Chem, vol. 5, no. 3, pp. $468-475,2010$.

[62] J. Tian, K. K. Wong, C. M. Ho et al., "Topical delivery of silver nanoparticles promotes wound healing," Chem Med Chem, vol. 2, no. 1, pp. 129-136, 2007.

[63] T. D. Nguyen, T. T. Nguyen, K. L. Ly et al., "In vivo study of the antibacterial chitosan/polyvinyl alcohol loaded with silver nanoparticle hydrogel for wound healing applications," International Journal of Polymer Science, vol. 2019, Article ID 7382717, 10 pages, 2019.

[64] X. Zhao, B. Guo, H. Wu, Y. Liang, and P. X. Ma, "Injectable antibacterial conductive nanocomposite cryogels with rapid shape recovery for noncompressible hemorrhage and wound healing," Nature Communications, vol. 9, no. 1, pp. 1-17, 2018.

[65] J. Qu, X. Zhao, Y. Liang, T. Zhang, P. X. Ma, and B. Guo, "Antibacterial adhesive injectable hydrogels with rapid selfhealing, extensibility and compressibility as wound dressing for joints skin wound healing," Biomaterials, vol. 183, pp. 185-199, 2018

[66] B. Zhang, J. He, M. Shi, Y. Liang, and B. Guo, "Injectable selfhealing supramolecular hydrogels with conductivity and photo-thermal antibacterial activity to enhance complete skin regeneration," Chemical Engineering Journal, vol. 400, p. 125994, 2020.

[67] M. Li, Y. Liang, J. He, H. Zhang, and B. Guo, “Two-pronged strategy of biomechanically active and biochemically multifunctional hydrogel wound dressing to accelerate wound closure and wound healing," Chemistry of Materials, vol. 32, no. 23, pp. 9937-9953, 2020.

[68] X. Zhao, Y. Liang, B. Guo, Z. Yin, D. Zhu, and Y. Han, "Injectable dry cryogels with excellent blood-sucking expansion and blood clotting to cease hemorrhage for lethal deep-wounds, coagulopathy and tissue regeneration," Chemical Engineering Journal, vol. 403, p. 126329, 2021. 